\title{
Peer review-the "who" and the "how"
}

In an earlier editorial, we gave recognition to 227 persons who reviewed manuscripts for Tobacco Control from late 1993 to the end of $1995 .{ }^{1}$ Appended to this editorial is another list of 227 individuals - those who reviewed papers for the journal as outside referees or co-editors in 1996 and 1997. This list includes those who reviewed papers for two special supplements to the journal which were published in 1997..$^{2-3}$ As usual, we express our appreciation to them all, as the quality of the journal depends on the vital service they perform.

In a 1993 editorial I explained how we performed peer review at that time. ${ }^{4}$ We have used a rigorous peer-review process since the inception of the journal, but that process has been refined and strengthened in recent years. So I'll take this opportunity to explain how we now conduct peer review at Tobacco Control.

The most significant change is the use of an editorial committee which makes consensus decisions on papers submitted to the journal. The committee, modelled after a similar committee used by the $B M \mathcal{F}$, is often referred to internally as the "hanging committee". That name did not originate from the macabre meaning of the word "hang"; rather, it is borrowed from the Royal Academy of Arts in London, which has used a "hanging committee" to decide which paintings to hang on its walls (personal communication from Dr Richard Smith, editor of $B M F$ ).

Before 1997, I myself made interim and final decisions on papers-whether to accept or reject them, or to send them back to authors for revisions. Those decisions were aided by comments from peer reviewers and recommendations made by senior and associate editors. Beginning with papers submitted in January 1997, editorial decisions have been made by our three-member hanging committee, consisting of myself and our two senior editors-Drs Ross Brownson and $\mathrm{K}$ Michael Cummings. Dr Brownson is professor and chair of the Department of Community Medicine at Saint Louis University's School of Public Health. Dr Cummings is chair of the Department of Cancer Control and Epidemiology at Roswell Park Cancer Institute in Buffalo, New York. The hanging committee meets weekly by conference call.

When papers arrive at our editorial office, they are assigned to Dr Brownson or Dr Cummings on an alternating basis, so that one of them takes the lead on each paper. At the next conference call, the lead senior editor makes a recommendation to the committee as to whether a new paper should be rejected outright or sent for external peer review. If the paper is designated for peer review, the committee identifies referees to whom the paper will be sent. Generally we send papers to three peer reviewers, so that if one reviewer is unable or unwilling to review it, we are left with two others who can. If a paper has substantive data analysis, it is also sent to one of our three consulting editors for methods and statistics: Dr Seth Emont, a senior programme officer at the Robert Wood Johnson Foundation; Dr Todd Rogers, who until recently was a senior research scientist (for more than a decade) at Stanford University's Center for Research in Disease Prevention; and Dr Michael Siegel, an assistant professor at Boston University's School of Public Health.

Tobacco Control has 12 associate editors, each of whom covers a distinct area in tobacco control for the journal. The associate editors, and the areas they handle, are shown on the inside front cover of the journal. If the subject matter addressed by a paper falls within the purview of an associate editor, we will often request assistance from that individual. In that circumstance, the associate editor will typically nominate peer reviewers for the paper, and will make recommendations to the hanging committee concerning the disposition of the paper (accept, reject, revise) as it goes through the various stages of editorial and peer review. In some cases the associate editor carries on correspondence with the author.

When peer review is completed on a paper, or when a revised paper is received from an author, it is placed on the agenda of the next conference call. Relevant materials for each manuscript on the agenda are distributed in advance to each of the three members of the committee. During the call, the senior editor who has the lead on a particular paper summarises the content of the manuscript; the feedback from those who reviewed the paper (outside referees, the consulting editor for methods and statistics, and the associate editor); and in the case of a revised paper, the changes made to the earlier version. After discussion, the committee reaches a consensus decision, representing interim or final action on the paper. With very few exceptions, decisions of the hanging committee are unanimous.

When we request that authors revise their paper, we provide them with "blinded" copies of peer review comments to guide them in their revisions. When we reject manuscripts, we also send authors the comments from peer reviewers, to help the authors improve their papers should they wish to resubmit them to another journal.

In addition, we usually share all the peer review comments (with identifiers removed) and our letters to authors with each of the reviewers. This gives them feedback on editorial decisions regarding the paper and allows them to compare their own judgments on the manuscript with those of their peers.

The hanging committee approach yields several benefits. First, three editors make joint decisions based on careful review and discussion; thus, decisions are more likely to be well-informed, fair to the authors, and free from any bias that one particular editor might bring to the table. Second, the approach distributes the workload among three individuals, which allows papers to be handled more efficiently. Third, a weekly meeting agenda ensures that the process moves forward continuously. In a future editorial, we will report trend data on how quickly decisions are made on manuscripts, how long it takes for accepted papers to be published, the number of papers submitted, and the percentage that are accepted for publication.

As we have noted previously, ${ }^{1}$ the peer review process is far from perfect, but it is the best form of quality control we have in "journalology". We will continue to strive to improve the process, and we welcome comments on how to do so from our readers and contributors.

\section{Editor}

RONALD M DAVIS

1 Davis RM, Chapman S. Peer reviewers-November 1993 to December 1995. Tobacco Control 1996;5:4-6.

2 AHCPR Smoking cessation guideline: its goals and impact. Tobacco Control 1997;6(suppl 1):S1-99.

3 Studies in community tobacco control: projects COMMIT and ASSIST. Tobacco Control 1997;6(suppl 2):S1-70.
The

4 Davis RM. Two years of Tobacco Control: how are we doing? Tobacco Control 1993;2:265-6. 


\section{Peer reviewers-1996 and 1997}

Jasjit S Ahluwalia

David G Altman

Amanda Amos

Charles Atkin

Ann Baker

Dileep G Bal

John Baron

Karl E Bauman

John Beasley

Diane M Becker

Ramez N Bedwani

Michael E Begay

Neal L Benowitz

James Bergman

Lisa A Bero

Alan J Best

Lois Biener

Michele Bloch

John Bloom

Richard J Bonnie

Ron Borland

Deborah J Bowen

Rick Boyd

Ross C Brownson

Germaine Buck

David M Burns

Dee Burton

Tom Carroll

Frank J Chaloupka

Simon Chapman

Anne Charlton

T L Chen

Pam Clark

Valerie A Clarke

Richard Clayton

Joel Cohen

Stuart Cohen

Graham Colditz

Gregory N Connolly

Terry L Conway

Thomas M Cooper

K Michael Cummings

Vera Luiza da Costa e Silva

James R Davis

Joseph R DiFranza

Mirjana V Djordjevic

Douglas W Dockery

Rob Donovan

Russ Eggert

John Elder

Sherry Emery

Karen Emmons

Seth L Emont

Virginia L Ernster

Daniel H Ershoff

Luis G Escobedo

Ruth A Etzel

Karl O Fagerström

Arthur Farkas

Roberta G Ferrence

Linda Ferry

Michael C Fiore

Paul M Fischer

Edwin B Fisher, Jr

Brian R Flay

Roberto Forero

Jean L Forster
Stephen Fortmann

Godfrey Fowler

Deborah A Galuska

John Garcia

Karen K Gerlach

Elizabeth Gilpin

Gary A Giovino

Stanton A Glantz

Russell E Glasgow

Thomas J Glynn

Marvin E Goldberg

Adam Goldstein

Michael Goldstein

Steven Gourlay

Nigel Gray

David Gregorio

Verner Grise

Ellen R Gritz

Janet Gross

Neil E Grunberg

Tyler D Hartwell

Gerard B Hastings

Anthony J Hedley

Jack E Henningfield

David Hill

Tom Hodgson

C D'Arcy Holman

Thomas P Houston

Philip P Huang

John R Hughes

Robert Hughes

Corinne G Husten

Andrew Hyland

Norm Hymowitz

Les Irwig

Peyton Jacob

Peter Jacobson

Carlos Roberto Jaén

Martin J Jarvis

Leonard A Jason

Christopher Jenkins

Murray J Kaiserman

Nancy Kaufman

Theodore E Keeler

Juliette S Kendrick

Joel Killen

Alan King

Robert C Klesges

Howard K Koh

Thomas E Kottke

Lynn T Kozlowski

T H Lam

Tim Lancaster

Harry A Lando

Scott J Leischow

Edward Lichtenstein

Daniel Longo

Alan D Lopez

Jay H Lubin

Douglas A Luke

Karl E Lund

William R Lynn

Lynn MacFayden

Judith L Mackay

Marc W Manley

Marian Marbury

Alfred C Marcus
Tim McAfee

Ian McAllister

Bruce McCarthy

Ann McNeill

Robin Mermelstein

Dawn Misra

Karen Monaco

Robert Morris

David Nelson

Paul Nordgren

Thomas E Novotny

Don Nutbeam

Judith K Ockene

Patrick O'Malley

C Tracy Orleans

Merete Osler

Deborah J Ossip-Klein

Bart D Ostro

Neville Owen

Michael D Parkinson

John L Pauly

Neal Pearce

Linda L Pederson

Cheryl L Perry

Diana B Petitti

John M Pinney

Phyllis Pirie

Richard W Pollay

David Pollock

Paul Pomrehn

James O Prochaska

Alexander Prokhorov

Cynthia Rand

Donald J Reid

Patrick L Remington

Stephen Rennard

James L Repace

Dorothy P Rice

Robyn Richmond

Michael Robbins

Robert G Robinson

Todd Rogers

Lynn Rosenberg

Jonathan M Samet

Rob Sanson-Fisher

Margot Schofield

Joel Schwartz

Randy Schwartz

Russell Sciandra

Michelle Scollo

Herbert H Severson

Donald J Sharp

Saul Shiffman

Robert Shipley

Donald R Shopland

Michael Siegel

Chris Silagy

Karyn Skaar

John Slade

Karen Slama

LeifI Solberg

Laura J Solomon

Eduardo J Somoes

Glorian Sorensen

Kyle Steenland

Frances Stillman

Maxine L Stitzer 
Jeffrey J Stoddard

Steven Y Sussman

David Sweanor

Martin Taylor

Beti Thompson

Michael J Thun

Per Tillgren

Scott L Tomar

Fernand Turcotte
D G Uitenbrock

Sverre Vedal

Wayne F Velicer

Melanie Wakefield

Michael Wall

Larry Wallack

Kenneth E Warner

Thomas K Welty

David W Wetter
Gary Whitlock

Marianne B Wildey

Stephen Woodward

John K Worden

Anna H Wu

Derek Yach

James P Zacny

Shu-Hong Zhu

\section{Stepping down}

Having served as editor of Tobacco Control for the past seven years, I have decided to step down from this position. Since the journal's launch in 1992, we have made great strides with the publication, and the positive feedback we've received from readers, authors, and many others has been gratifying. One of the most enjoyable aspects of my service as editor has been the opportunity to work with a superb team of co-editors, and with friends and colleagues at the BMJ Publishing Group who define the word "professional". But it is time for me to move on to other challenges, and to let others take over the helm.

An advertisement recruiting candidates for the editorship appears below. I expect to pass the reins to the new editor early in 1999 . Before then, in a future editorial, I will take the liberty of sharing with you more thoughts and reflections about the roles and accomplishments of the journal.

\section{EDITOR}

\section{Tobacco Control}

Specialists with an interest in research, analysis, commentary and debate on policies, programmes and strategies that are likely to further the objectives of a comprehensive tobacco control policy world wide are invited to apply for the post of Editor. Please send a letter of application, a curriculum vitae, and a short statement about the strengths and weaknesses of Tobacco Control and your proposed editorial policy. Full Editorial support will be provided and it is envisaged that the Editor will need to devote about 8-12 hours a week to the journal. Applications from specialists outside the UK and joint applications from two or more candidates wishing to act as co-Editors will be welcomed.

Closing date is 31 st October 1998. Interviews will be held shortly thereafter to enable the successful candidate(s) to take up the post from January 1999.

\section{RIVI}

Applications or requests for further information about the post should be sent to:

Mrs Alex Williamson

BMJ Publishing Group

BMA House

Tavistock Square

London WC1H 9JR

Tel: $\quad+441713836069$

Fax: $\quad+441713836668$

E mail: AlexWilliamson@compuserve.com 